
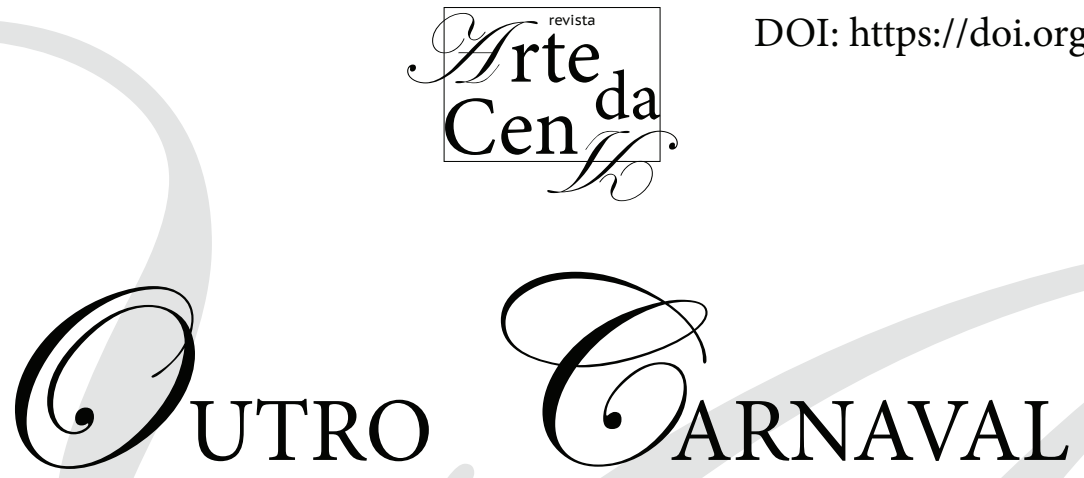

\title{
FESTA E PERFORMATIVIDADE EM PROTESTOS DO BRASIL PÓS-TEMER
}

"Another Carnival: Party and Performativity in post-Temer Brazil"

\author{
Christina Gontijo Fornaciari* \\ Departamento de Artes e Humanidades \\ Universidade Federal de Viçosa
}

RESUMO: O presente artigo pretende olhar para manifestações políticas realizadas pela população no Brasil pós-Temer, analisadas pelo viés da teoria da performance e da filosofia. Para tanto, utilizaremos o pensamento de autores como Richard Schechner, Michael Bakhtin, Antônio Negri, Michael Hardt, Graeme Chesters e Ian Welsh, entre outros, como fundamento para nossa apreciação de tais fenômenos políticos. Esses pensadores nos fornecem conceitos que nos conduzem, a título de conclusão, a considerar que "ação para revolução", "carnavalização", "multidão" e "frivolidade tática" são termos que poderiam ser alinhados aos novos modos de protestar emergentes no período histórico vigente.

Palavras-chave: performance; política; artivismo.

\begin{abstract}
The present article intends to look at the political manifestations in the streets of Brazil post-Temer, analysing them through the gaze of theories of performance and philosophy. To do so, we will use key concepts such as "action for revolution", "carnavalisation", "multitude", "tactical frivolity", drawn from the thinking of Richard Schechner, Michael Bakhtin, Antônio Negri, Michael Hardt, Graeme Chester and Ian Welsh, among others, in order to understand these new types of protests emerging on present historical period.
\end{abstract}

Keywords: performance, politics, artivism.

Christina Gontijo Fornaciari - Outro Carnaval: festa e performatividade em protestos do Brasil pós-Temer. Revista Arte da Cena, Goiânia, v. 3, n. 2, p. 18-30, jul-dez/2017. 


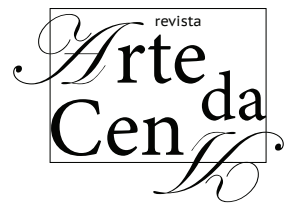

\section{Introdução}

Gostaria de começar este texto identificandome como cidadã brasileira, professora de artes e artista. Minhas atividades profissionais na universidade, bem como minhas práticas artísticas, estão relacionadas e orientadas por um profundo interesse no domínio político das artes. No entanto, não me considero alinhada a qualquer partido. A escolha por utilizar a ascensão de Michel Temer ao cargo de Presidente da República não representa posicionamento contrário ou favorável a esse fato, por parte da autora que vos escreve. Tal recorte se deu meramente por questões temporais e históricas, ligadas à observação de uma ocorrência mais intensificada de formas diversas de protestar, neste período. $\mathrm{O}$ ato de escrever sobre o novo rosto das manifestações políticas no Brasil desperta lembranças que trago desses eventos, misturadas com experiências artísticas e, de certa forma, alinhavadas por teorias sobre performance. É dentro desta tríade que pretendo basear o seguinte texto. Vale ressaltar ainda que a escolha por escrever em primeira pessoa foi determinada pela característica participativa das análises propostas, que se pode verificar ao longo do texto, uma vez que estive inserida no que está, agora, sendo objeto de minha reflexão.

Estive em recentes manifestações políticas no Brasil em três momentos decisivos: em junho de 2013, quando houve uma luta por melhores condições sociais impulsionadas pela vinda da Copa do Mundo ao Rio de Janeiro; entre 2015 e início de 2016, durante o movimento para a remoção da presidente Dilma Rousseff; e após Michel Temer subir à presidência, em maio de 2016. Comparando esses três momentos, podese dizer que os protestos tornaram-se mais leves e menos violentos ao longo das três instâncias, passando dos mais impetuosos em 2013 para os mais festivo nos últimos tempos.

A pressão que explodiu em 2013 fez com que os protestos de rua se manifestassem de uma forma muito dura e violenta, com uma presença elevada de grupos do Black Bloc, lojas, bancos e edifícios públicos sendo depredados e pessoas feridas, tanto por manifestantes quanto pela polícia. Manifestantes oriundos de estratos mais baixos da sociedade constituíam a maioria nessas manifestações. Por outro lado, o movimento 2015/2016 dos chamados "paneleiros" que empurraram para o impeachment a (agora) expresidente Dilma Rousseff, tomou uma forma totalmente diferente, em termos de estratos sociais (na maior parte constituída pela classe média alta), reivindicações políticas (todos empurrando para o mesmo objetivo: a renúncia/expulsão de Dilma) e a forma dos protestos (menor duração, menos pessoas nas ruas, protestos organizados em casa). 


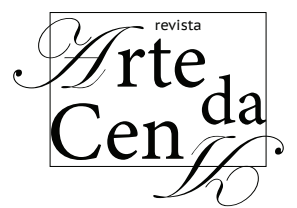

Naquele momento já havia um elemento de ironia no ar, como o uso de símbolos satíricos - por exemplo, um pato amarelo, batizado como o FIESP (esse pato se tornaria o símbolo da corrupção na Federação Brasileira das Indústrias, uma vez que temos um ditado no Brasil que diz como "quem vai pagar o pato?", que é usado para perguntar quem vai ser responsabilizado por algo que está muito errado), coreografias de Fora Dilma, um slogan irônico “Tchau, Querida”, para expressar o impeachment de Dilma e o ato coletivo de bater panelas sempre que Dilma Rousseff estivesse na TV: nessas ocasiões, alguém ouviria o som de panelas nos bairros mais ricos e até mesmo em algumas periferias, de todas as grandes cidades no Brasil, mas a violência direta e a pressão diminuíram drasticamente em comparação com os protestos nos dias de junho e julho de 2013.

Enquanto isso, os protestos atuais parecem ter diluído a violência ainda mais radicalmente, com a atmosfera mais próxima de uma festa, uma celebração, uma ocupação da rua. Não seria exagero vincular essas características à descrença nas instituições políticas. O sarcasmo e a jovialidade dos protestos atuais não visam defender a Presidenta, mas sim, parecem revelar essa descrença generalizada na "classe" política, bem como uma preocupação em manter as ruas vivas e livres para as pessoas. Tal comportamento releva um entendimento de que essa nova forma de política, menos severa e mais divertida, pode ser mais eficaz na medida em que o confronto direto e partidarizado é substituído por uma implementação efetiva do direito à cidade.

Além disso, vemos em protestos hoje em dia uma mistura maior de perfis de cidadãos, provenientes de estratos sociais diferentes e buscando diferentes objetivos: há aqueles que querem eleições diretas (eles usam o hashtag \# DiretasJá), outros que só querem a deposição de Michel Temer (\#ForaTemer), uma terceira ala que deseja o retorno da Ditadura Militar (\#DitaduraJa), outra facção de pessoas que desejam a restauração de Dilma para o cargo de presidente (\#VoltaDilma) e, no entanto, aqueles que estão "contra tudo e todos "(\#ForaTodos).

\section{Performatividade(s) ManiFestas}

Esse comportamento multifacetado pode ser entendido à luz do texto de Richard Schechner "What is Performance?" retirado de seu livro "Performance Studies - an introduction" (2006). $\mathrm{O}$ estudioso americano se refere às atividades da vida pública - especificamente citando carnavalescos e manifestações políticas coletivas - como performances do corpo social, ressaltando que a multiplicidade de agentes e desejos nos protestos caracterizariam o que o autor chama 
de "Ações para a Revolução" (2006, 4). Assim, uma situação política seria caracterizada onde os participantes resistem, embora não encontrem senso comum. Em suas palavras:

As atividades da vida pública - às vezes calmas, às vezes tumultuadas; às vezes visíveis, outras mascaradas - são performances coletivas. Essas atividades vão desde políticas sancionadas até manifestações populares e formas de protesto, e até mesmo a revolução. Os agentes dessas ações pretendem mudar as coisas, manter o estado das coisas ou, mais comumente, encontrar ou definir um lugar comum. Uma revolução ou uma guerra civil acontece quando os envolvidos não desistem e não há senso comum entre eles. (SCHECHNER, 2006, 3)

Durante as Manifestações pós-Temer, há uma dupla sensação dessa performatividade citada por Schechner: uma repetição de comportamentos sociais anteriores - percebida no próprio ato de protestar, como algo já enraizado na cultura política de várias sociedades - e, por outro lado, uma ruptura na seriedade e peso com que os protestos eram geralmente conduzidos, dando origem a novas formas de performatividade, em atmosferas festivas.

Esta atmosfera festiva tem sido acompanhada de um comportamento "socialmente liberado", típico das festas e que também é característico desses momentos, suspendendo temporariamente as "regras de uma hierarquia opressiva". Essas performances sociais realizadas nos protestos constituem-se como momentos extraordinários, destacados da rotina e marcados por alegria e por valores considerados altamente positivos. Enquanto a rotina da vida diária é aquela que é vista como negativa. (DAMATTA, 1997, 99)

Nesta perspectiva, a introdução da performance social apresenta-se como uma ferramenta que proporciona uma mudança na vida individual ou social de um grupo, mesmo antes do direito reivindicado ser implementado. Por isso, percebemos a ocorrência do que o sociólogo brasileiro Rudá Ricci salienta em seu livro "Nas ruas" (2014) como "carnavalização política”, um conceito percebido pelo autor já em 2013, durante as manifestações de junho, que foi definido como:

Uma expressão da utopia popular, separada dos rituais formais e institucionais. Uma festa carnavalizada é uma transgressão autorizada, que degrada as autoridades, banaliza o poder estabelecido e cria novas identidades. Este potencial registrado na cultura brasileira foi atualizado nas demonstrações de junho. Pôsteres, máscaras, danças, t-shirts, adesivos, banners, agrupamentos uniformizados, havia tudo. (RICCI, 2014, 34)

Eu vivi minhas próprias experiências com a carnavalização, já que tive a oportunidade de participar de algumas manifestações que ocorreram em Belo Horizonte, capital de Minas Gerais e também na cidade de Viçosa, no interior mineiro. Em ambas as cidades, houve protestos 
engendrados em um modus operandi que usava a ambiência festiva e o humor como táticas para inaugurar modos de confronto não-violentos. Essas performances do corpo social promoveram instâncias de uma experiência política que, além de tudo, foi alimentada por uma estética de ironia, risada, prazer e celebração.

Slogans, cartazes engraçados e ativistas ridículos jogam com protestos sérios, combinando personagens incomuns, como palhaços, fadas, torcedores, LGBTQ, baterias de carnaval, coreografias e flash mobs.

$\mathrm{O}$ aspecto performativo de manifestações deste tipo foi batizado como "Frivolidade Tática" pelos sociólogos e professores ingleses Graeme Chesters e Ian Welsh (2007), quando os autores falam e estilo de ativismo chamado "Pink and Silver Bloc":

A frivolidade tática é uma forma de protesto público (...) muitas vezes descrito como um espaço que existe na distância entre realização total e o confronto violento. Esta estratégia procura desvendar as táticas de confronto multiplicando as linhas da frente e fazendo uso extremamente irônico da feminilidade e das representações kitsch do corpo em ação direta. A música e a dança proporcionaram essa redefinição radical do protesto de rua, não só com uma poderosa ferramenta para dissolver ou desviar a violência policial, mas também com a imagem mais forte possível (e trilha sonora) para perceber como as manifestações de rua podem se tornar o desencadeamento dos desejos do corpo no momento do próprio protesto. (CHESTERS e WELSH, 2007, 16)

Como o nome diz, o "Pink and Silver Bloc" usa um conjunto de cores para se diferenciar de outros grupos, como o Black Bloc (preto), ou partido comunista (vermelho). Chesters e Welsh (2007) relatam que o "Pink and Silver Bloc" surgiu de um movimento chamado "Reclaim the Streets" (RTS) que realizou festas - ou ações diretas anticapitalistas - em cidades como Londres, Tel Aviv, Sydney, Nova York e Helsínque na década de 1990.

Suas características podem ser comparadas aos protestos realizados no Brasil pós-Temer, já que ambos apresentam traços de festa, de delírio coletivo, teatro de rua e manifestação política. Eles trabalham criando atos de resistência que são poderosos gestos poéticos e estratégias políticas efetivas. Essas festividades políticas de rua recuperam o espaço urbano, utilizado até agora como uma malha para o capitalismo, o consumismo e o transporte privado, substituindoos por zonas temporárias autônomas: espaços vivos e vibrantes anteriormente proibidos aos pedestres.

O caráter poético e irreverente dessas manifestações as distancia das estratégias ineficazes dos grupos partidários, cujas atuações

Christina Gontijo Fornaciari - Outro Carnaval: festa e performatividade em protestos do Brasil pós-Temer. Revista Arte da Cena, Goiânia, v. 3, n. 2, p. 18-30, jul-dez/2017. 
costumam se limitar a passeatas atrás de um caminhão de som, onde um líder que discursa monotonamente, aos berros, é seguido por sonâmbulos sacudindo bandeirinhas de papel. Ao contrário, os novos protestos costumam atuar com música ao vivo ao invés de som elétrico, com instrumentos de sopro e bateria tocados em pequenos grupilhos, distribuídos ao longo da avenida ou do local onde se protesta. Alguns tocam, todos cantam, dançam, brincam uns com os outros em relação muito mais próxima e horizontal que os caminhões de som tradicionais. Ao invés dos uniformes monocromáticos, esses manifestantes costumam se vestir de forma idiossincrática, como fantasias de carnaval propriamente ditas, que não necessariamente se relacionam com o contexto do protesto. Outras vezes as vestimentas podem ser improvisadas ali mesmo, com sprays, estêncil ou adesivos.

As manifestações geram imagens e sons de irreverência e força, as quais são, então, sugadas por uma cobertura midiática colaborativa, celulares na mão. O material produzido nestes meios portáteis, espalhados por toda a multidão, eventualmente acaba em redes sociais, alimentando uma teia de “meta-performances" do corpo social. A repetição de imagens de rua, muitas vezes focada na violência, nestas ocasiões foi desviada para uma sensação de festa, risos e escárnio.
Longe da dominação das classes dominantes e dentro de uma economia de carnavalização política, o efeito produzido pelo fluxo dessas imagens nas redes, circulando e re-alimentando a organização do movimento, atuou de forma externa e independente do sistema convencional. Em um cenário de efervescência cultural, a circulação dessas imagens poéticas, muitas vezes não polidas, dá ao espectador uma sensação de hiperconsciência.

As imagens que circularam foram produzidas pelas próprias entranhas do movimento, nas estruturas rizomáticas deste corpo social, não de fora para dentro. Assim, as imagens das ruas dava às manifestações um caráter espetacular, mas não no sentido criticado por Debord, para quem o espetáculo "não é um conjunto de imagens, mas uma relação social entre pessoas, mediatizada por imagens, característica perversa do capitalismo e seus efeitos nas relações sociais". (DEBORD, 1967: 10)

Enquanto Debord vai afirmar que a produção e mercantilização destas imagens, levadas como ferramentas de poder pelas classes dominantes, submete os indivíduos a um processo de alienação, tornando-os induzidos a aceitar o que vêem como uma verdade absoluta, a circulação dessas imagens e a relação social que dela nascia era de outra natureza. Porém, da

Christina Gontijo Fornaciari - Outro Carnaval: festa e performatividade em protestos do Brasil pós-Temer. 


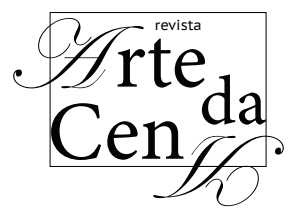

forma como ocorreu a disseminação de imagens, longe do domínio das classes dominantes e dentro de uma economia própria da "carnavalização política" parece-nos, como já afirmamos, que o efeito produzido seja o oposto de alienação: uma hiperconsciência.

Essas imagens são formas de capacitação do movimento, precisamente porque criadas pela própria multidão. A filósofa brasileira Kátia Silvestri estuda a carnavalização como a inorganização política de uma multidão de sujeitos que transgridem relações de poder. Ela argumenta que a carnavalização é a prática de reverter, mudar, virar o mundo de cabeça para baixo. A autora localiza nas manifestações populares que circulam (circularidade própria da tensão entre ideologia oficial e diária) pela sociedade, os próprios sinais de resistência que desarticulam as relações de dominação. Carnavalizar o protesto seria, então, uma forma de encontrar a transgressão dentro mesmo do ato de demonstrar o desejo político por mudança.

Assim, confiamos nesta tese para entender a carnavalização não só no plano estilístico dos protestos - suporte escrito e visual -, mas também como um alcance ético em sua dimensão estética, como experiências vividas, como uma produção da ideologia cotidiana.
Mais precisamente, Silvestri nos aponta para a necessidade de

(...) entender que a lógica da carnavalização é a lógica do reverso, do grotesco - uma prática alternativa aos discursos centralizadores e institucionalizados e, portanto, uma centrifugação inalienável da criação e da vontade humana. (SILVESTRI, 2014, 23)

A autora continua a discutir as teorias da carnavalização (BAKHTIN, 2006-2010) e a multidão (NEGRI e HARDT, 2004), discursos problematizantes sobre relações de poder, identidades e ações éticas-responsivas, elaborando um corte na análise que propõe elos entre carnavalização e multidão de sujeitos singulares.

Segundo Silvestri, em Bakhtin, ler a realidade significa problematizar os choques ideológicos produzidos pelos sujeitos entrevistados. Desta forma, a carnavalização como insurreição do cotidiano é uma política cujo projeto é desmantelar discursos ideológicos oficiais, desestruturação de identidades e relações de dominação. Para isso, o autor acrescenta o conceito de multidão de Negri e Hardt: essa união de singularidades que, em nome de um domínio comum - o desejo de desbalancear as práticas opressivas - transgredir, reverter, deslocar e remodelar as relações de poder de várias maneiras (como festas, protestos, folclores, livros, filmes, blogs, entre outros) e se expressam como corpos grotescos que são a base da ação do carnaval.

Christina Gontijo Fornaciari - Outro Carnaval: festa e performatividade em protestos do Brasil pós-Temer. 
É a noção de singularidade que se opõe à noção de identidade (fixa, coesa e solidamente constituída), que não permite confundir o conceito de multidão com o da massa. Para Negri e Hardt, a multidão é o duplo, o inverso de uma subjetivação capitalista em formatos de massa. Ou seja, a multidão de singularidades aterroriza, desestabiliza e desafia estruturas hierárquicas de dominação. O mesmo ocorre na carnavalização, para Bakhtin: essas manifestações populares trazem consigo um valor de inversão, um princípio destrutivo dos discursos e, como dito, também a desconstrução de identidades e relações de dominação.

Acrescentamos a este escrito algumas imagens de "Glitter Block", um grupo de atuação de ativismo brasileiro liderado pelo artista e docente da UFSC - Universidade Federal de Santa Catarina, Fabio Salvatti. Suas performancesprotestos exemplificam como as manifestações políticas de frivolidade tática visam combater a burocratização da própria maneira de protestar, instaurando um novo estado das coisas já desde o momento em que tais estados são demandados.

Assim, além de alinhar conceitos como carnavalização e multidão, novamente propomos que comparemos essas imagens de frivolidade tática ao que Guy Debord defendeu em 1967:
Não é apenas pela sua hegemonia econômica que a sociedade que transporta o show domina as regiões subdesenvolvidas. Ele os domina como a sociedade do espetáculo. Onde a base material ainda está ausente, a sociedade moderna já invadiu espetacularmente a superfície social de cada continente. Oferece aos revolucionários locais os falsos modelos de revolução. O próprio espetáculo do poder burocrático de alguns países industrializados é precisamente parte do espetáculo total, como seus pseudônimos gerais e seu apoio. Se o espetáculo, visto em seus vários locais, mostra especialidades totalitárias da palavra e da administração social, eles são incorporados em uma divisão global de tarefas espetaculares no funcionamento global do sistema. (DEBORD, 1967, 7)

As falas (em imagens, faixas, cartazes, frases na internet, gritos de guerra nas ruas, etc.) são proferidas por todos, sem depender de uma chancela instituída por poderes externos. A multiplicidade de vozes, característica da multidão, aponta para uma difusão de causas não especificadas. O sociólogo e estudioso de protestos de rua, Manuel Castells, ao falar sobre as manifestações brasileiras de 2013, já aponta esse fato como o grande trunfo do movimento, uma vez que espelha a multiplicidade de espectros políticos e a não divisão entre atuantes ativos e passivos.

Para o sociólogo, o espaço público reúne e dá voz, nestas ocasiões, a sociedade em sua mais ampla diversidade, incluindo a direita, a esquerda, os malucos, os sonhadores, os realistas,

Christina Gontijo Fornaciari - Outro Carnaval: festa e performatividade em protestos do Brasil pós-Temer. 
os ativistas, os piadistas, os revoltados e uma infinidade de interesses (CASTELLS, 2013), sem divisão entre quem está dentro e fora, propondo e consentindo. Todos constituem parte igualmente importante no movimento, sem hierarquia.

Um pensamento desenvolvido pelo sociólogo e filósofo de arte Miguel Chaia (2012) também contribui neste debate, ao comparar os manifestantes aos artistas do movimento situacionista: o autor afirma que de imediato, ambos tendem a aproximar-se da anti-arte, ao eliminar o objeto artístico em favor da intervenção social inspirada pela estética e ao desconsiderar a contemplação em benefício do envolvimento da comunidade. Ao assim fazer, os sujeitos produzem conceitos ou práticas, tendo por base uma consciência crítica aguçada, portada pelo artista individual ou por um coletivo. O uso de métodos colaborativos de execução do trabalho e de disseminação dos resultados obtidos é característico desse tipo de arte política, onde figura também a abordagem não-panfletária, muitas vezes baseada no humor e em táticas que possam mediar ou mesmo evitar o surgimento de violência e dos conflitos. Nas palavras do pesquisador paulistano:

Localizado no interior de uma relação social, o artista manifestante situa-se em posição que engendra uma esfera relacional fundada no desejo de luta, na responsabilidade ou na vocação social. Ele reconhece a existência de conflitos a serem enfrentados de imediato, assim como reconhece o outro. Neste forte envolvimento social, tem-se reduzida a autonomia da arte, e, em contrapartida, amplia-se a relação entre ética e estética (CHAIA, 2007: 11).

Por isso, pode-se dizer, amparados no pensamento de Chaia (2007) que, assim como nas manifestações, o núcleo gerador desse tipo de arteé a necessidade de resposta à realidade circundante. É assim que a performance e intervenção social realizam-se como atividades processuais, tanto na configuração, como na técnica, contra o objeto e seus sistema de circulação, estruturada pelo mercado. Deste modo o foco permanece no processo e os resultados que possam ocorrer são entendidos como conseqüências naturais de sua tática de ação.

De fato, Chaia (2007) afirma haver nelas um realismo político que busca o sucesso dos objetivos, seja no microcosmo (quarteirão ou bairro) seja no macrocosmo (público ampliado, áreas internacionais ou internet). $\mathrm{O}$ autor fala ainda em realismo também por incorporar à arte que nasce nesse contexto uma certa instrumentalização, um caráter concreto, real de aplicação social, dando a ela uma função sócio-política que vai desde a formação de consciência do outro, passando pela educação, até o fomento da mobilização. Pode-se ter então, nessas instâncias, o artista funcionando como

Christina Gontijo Fornaciari - Outro Carnaval: festa e performatividade em protestos do Brasil pós-Temer. Revista Arte da Cena, Goiânia, v. 3, n. 2, p. 18-30, jul-dez/2017. 
um gatilho disparador de futuros acontecimentos sociais, cuja detonação e desenrolar são a todo o tempo alinhados a um processo altamente criativo e coletivo.

Entendemos que esse aspecto delimita o âmbito da ação: que parte do individual, passa pelo coletivo e alcança insuspeitados espaços no qual se localiza o outro. Esta prática desloca o cenário da arte e da política para o espaço público. Sai do espaço fechado e branco para o espaço cinza das ruas ou para o espaço virtual da internet (CHAIA, 2007: 12).

Ainda segundo Chaia (2012), essas práticas inauguram espaços de sociabilidade, incorporando um conjunto de diversidades estéticas que se alastram desde o artista libertário, até o ativista programático, funcionando como um campo onde reinam as heterotopias, de modo similar ao carnaval.

Introduzindo o pensamento do sociólogo Néstor García Canclini (2013), ao refletir sobre a forma de avaliar a eficácia de ações culturais de jovens aparentemente despolitizados ou de baixo conhecimento específico de política (ele refere-se ao grafite e às performances de/em determinados protestos) o autor argentino aponta que essas ações, por seu forte aspecto performático, resultam em interrupções da ordem neoliberal e, por conseguinte, potencializam seus caráter estético enquanto anti-arte. Canclini continua exemplificando: eles - artivistas, globalistas, ambientalistas e grupos de direitos humanos - cortaram estradas, interromperam uma reunião da Organização Mundial do Comércio, fizeram o que se chama "escraches", reclamações públicas defronte à casa de um político corrupto ou ex-torturador impune na Argentina... (CANCLINI, 2013: 3)

Ainda segundo esse autor (2013), a Pesquisa Nacional da Juventude encontrou no México uma realidade que poderia ser aplicada a jovens em diversos países: eles estão dispostos a participar de causas, mas não de organizações. Embora existam várias formas de engajamento de um jovem interessado em questões sociais das mais variadas, como indigenistas, ambientalistas, de gênero, etc., uma característica comum é a sintonia com eventos ou manifestações que expressam a desconfiança em causas e/ou instituições que alegam representá-los, especialmente no plano da política. Ou seja, se interessam em atuar em instâncias da micropolítica que se distanciam da tomada de poder, no sentido comum.

De fato, o que nos parece curioso é que estudos culturais e antropológicos têm destacado, nos últimos anos, que essas manifestações não aspiram, em nenhum aspecto, um desejo político de tomar o poder ou controle do Estado, mas sim de uma alteração no seu modus operandi, o qual se inicia numa alteração do modus operandi da próprias manifestações. 


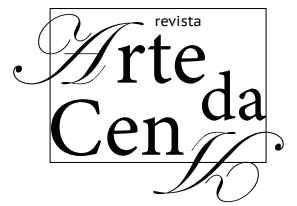

Como conclusão, podemos dizer que as manifestações carnavalizadas no Brasil pósTemer geraram, através do riso e do prazer, uma nova energia política que, como as celebrações populares, traz consigo algo transgressor: no momento momentâneo que abre nessas experiências, É como se a vida mudasse de curso. Este é o impulso crítico utópico da carnavalização e, também, é aí que a sua resiliência política aumenta.

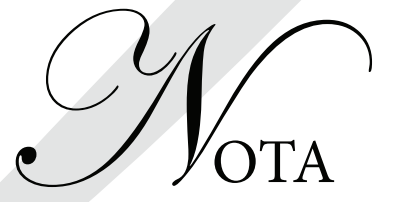

1 Heterotopia (aglutinação de hetero $=$ outro + topia = espaço) é um conceito da geografia humana elaborado pelo filósofo Michel Foucault que descreve lugares e espaços que funcionam em condições nãohegemônicas. Foucault usa o termo heterotopia para descrever espaços que têm múltiplas camadas de significação ou de relações com outros lugares, cuja complexidade não pode ser vista imediatamente. São os espaços das alteridades, que não estão nem aqui nem lá, que são simultaneamente físicos e mentais, tais como o espaço de uma chamada telefônica ou o momento quando alguém se vê no espelho.

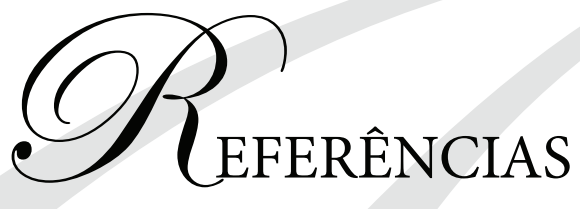

BAKHTIN, Michael. A Cultura popular na idade média e no renascimento: o contexto de François Rabelais. São Paulo: Hucitec, 2010.

BAKHTIN, Michael. Estética da criação verbal. São Paulo: Martins Fontes, 2006.

CANCLINI, García Néstor. Culturas Hibridas: Estratégias para Entrar e Sair da Modernidade. São Paulo: Edusp, 1998.

CASTELLS, Manuel. Redes de Indignação e Esperança: Movimentos sociais na era da internet. Rio de Janeiro: Zahar. 2013.

CASTELLS, Manuel. A sociedade em rede, v.1. São Paulo: Editora Paz e Terra, 1999.

CHAIA, Miguel (org.). Arte e política. Rio de Janeiro: Azougue, 2007.

CHAIA, Miguel (org.). Artivismo - Política e Arte Hoje. Revista Aurora, 1. São Paulo: PUC-SP, 2007, p. 9 a 12.

CHAIA, Vera e CHAIA, Miguel (orgs.). Mídia e política, Escritos. NEAMP, Estudos pós-graduados em ciências sociais, São Paulo: PUCSP, 2012.

CHESTERS, Graeme and WELSH, Ian. Complexity and Social Movements: Protest at the Edge of Chaos. London; New York: Routledge, 2006.

DAMATTA, Roberto. Carnavais, malandros e heróis. $6^{\mathrm{a}}$ ed. Rio de Janeiro: Rocco, 1997.

DEBORD, Guy. A sociedade do espetáculo. 


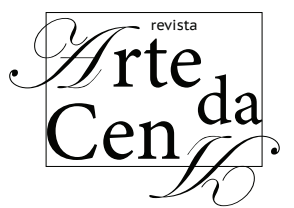

Paris, 1967. Electronic version: http:// www. ebooksbrasil.org/adobeebook/socespetaculo.pdf accessed in 08/08/2017.

HARDT, Michael e NEGRI, Antônio. Multidão: Guerra e democracia na era do Império. Rio de Janeiro: Record, 2004.

RICCI, Rudá e ARLEY, Patrick. Na Rua. Belo Horizonte: Letramento, 2014.

SCHECHNER, Richard. Performance Studies: a critical introduction. London: Routledge, 2006.

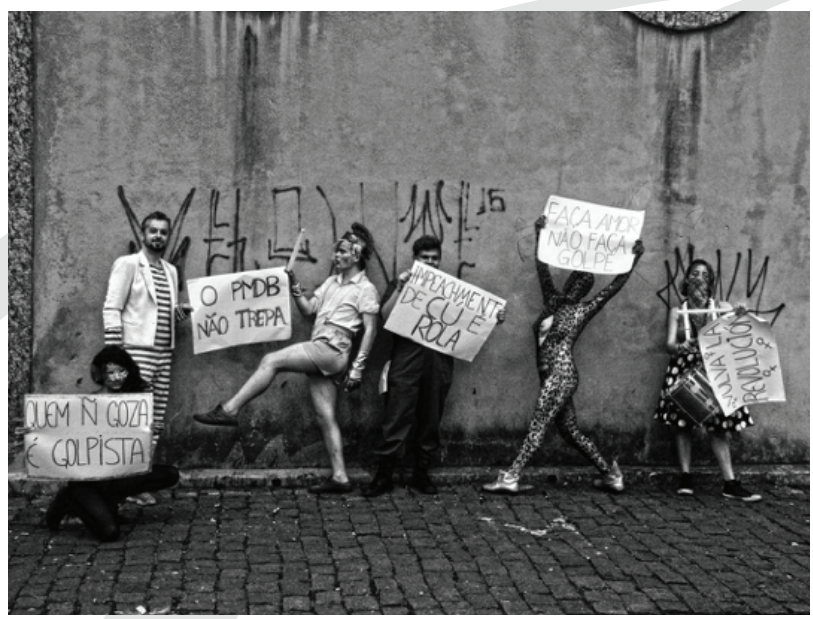

SILVESTRI, Katia Vanessa Tarantini. Carnavalização como transgrediência da multidão. Disponível em: http://site.ufvjm. edu.br/revistamultidisciplinar/files/2015/05/ K\%C3\%A1tia-Silvestri.pdf, accesso em 08/08/2017.

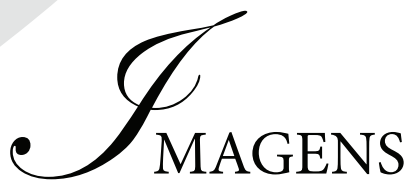

As imagens a seguir foram gentilmente cedidas por Fabio Salvatti, diretor e integrante do grupo de performance e ativismo "Giltter Block". As fotografias foram tiradas em suas aparições nas manifestações de 2016 na cidade de Florianópolis/SC.
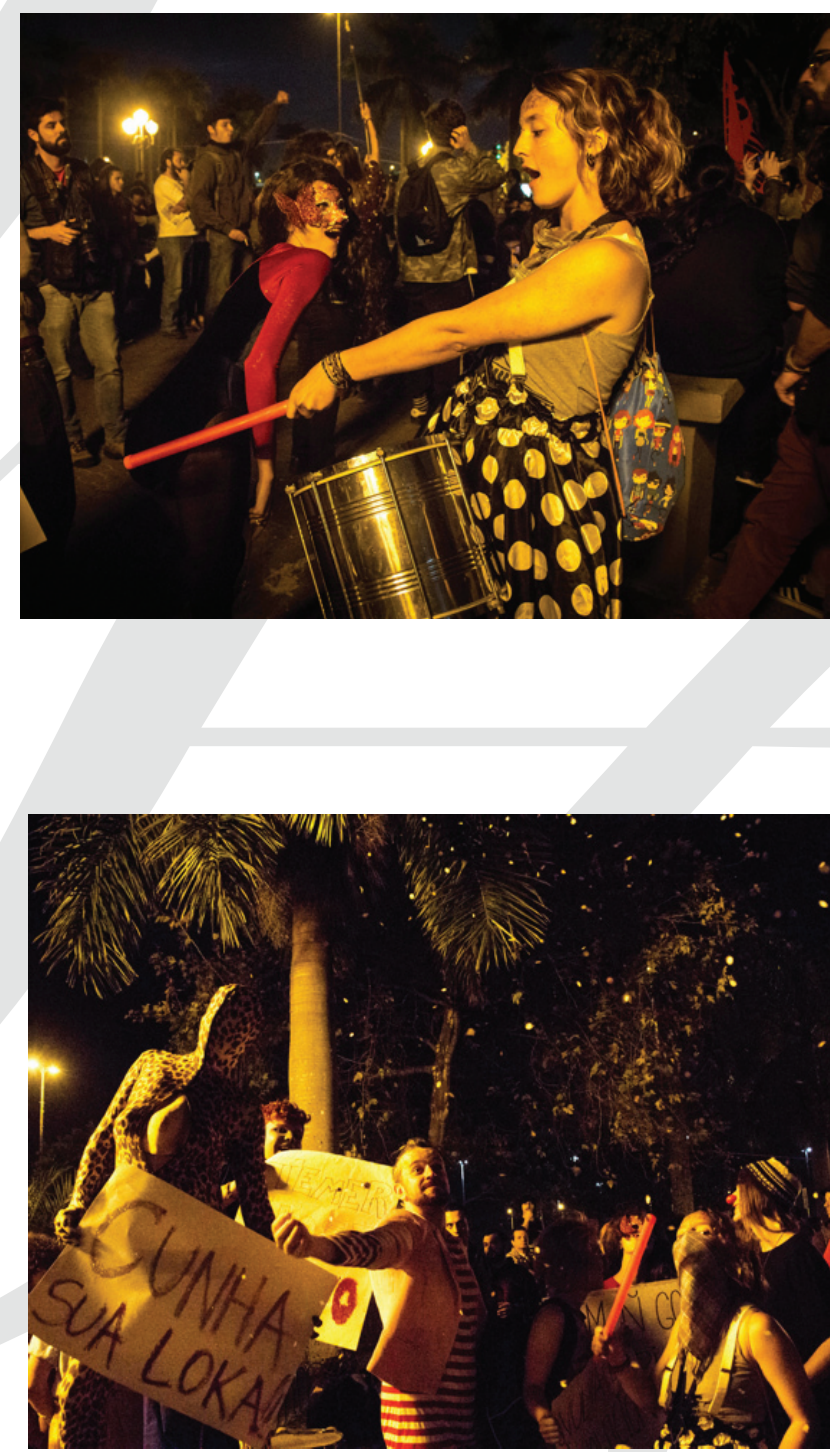

Christina Gontijo Fornaciari - Outro Carnaval: festa e performatividade em protestos do Brasil pós-Temer. Revista Arte da Cena, Goiânia, v. 3, n. 2, p. 18-30, jul-dez/2017.

Disponível em: http://www.revistas.ufg.br/index.php/artce 
* CHRISTINA GONTIJO FORNACIARI é Professora Adjunta no Curso de Dança da UFV - Universidade Federal de Viçosa/MG, desde setembro de 2015. Doutora em Artes Cênicas pela UFBA - Universidade Federal da Bahia (setembro 2014). Mestra em Performance pela Queen Mary, University of London (2005), com revalidação pela USP (2009) na linha de pesquisa Teorias e Práticas Teatrais. Pós-graduada em Gestão Cultural pelo Instituto Struzzo (ItáliaBrasil, 2008). Graduada em Direito pela Faculdade de Direito Milton Campos (2002). Formada no Curso Técnico de Formação de Atores do Teatro Universitário da UFMG (2000). Professora substituta na Faculdade de Educação da UFMG - Universidade Federal de Minas Gerais de julho 2013 a agosto de 2015. Professora substituta no curso de Licenciatura em Artes Cênicas na UFOP - Universidade Federal de Ouro Preto, de março de 2009 a março de 2011.

Artigo submetido em: 17/09/2017 Aprovado em: 26/12/2017

Christina Gontijo Fornaciari - Outro Carnaval: festa e performatividade em protestos do Brasil pós-Temer. Revista Arte da Cena, Goiânia, v. 3, n. 2, p. 18-30, jul-dez/2017. 